\title{
Heritage Languages: In the 'Wild' and in the Classroom
}

\section{Citation}

Polinsky, Maria, and Olga Kagan. 2007. Heritage languages: In the 'wild' and in the classroom. Language and Linguistics Compass 1(5): 368-395.

\section{Published Version}

http://dx.doi.org/10.1111/j.1749-818x.2007.00022.x

\section{Permanent link}

http://nrs.harvard.edu/urn-3:HUL.InstRepos:3382973

\section{Terms of Use}

This article was downloaded from Harvard University's DASH repository, and is made available under the terms and conditions applicable to Other Posted Material, as set forth at http:// nrs.harvard.edu/urn-3:HUL.InstRepos:dash.current.terms-of-use\#LAA

\section{Share Your Story}

The Harvard community has made this article openly available.

Please share how this access benefits you. Submit a story.

Accessibility 


\section{DRAFT}

\section{REVISED JUNE 8, 2007}

\section{Accepted for publication in}

\section{Language and Linguistics Compass}

\section{Heritage languages: in the "wild" and in the classroom \\ Maria Polinsky, Harvard, and Olga Kagan, UCLA}

\section{Introduction}

"There is no place for the hyphen in our citizenship....We are...not a polyglot boarding house," wrote Theodore Roosevelt in “The Square Deal in Americanism" (Roosevelt 1918). Had Roosevelt lived long enough to meet Jim, class of '09 at a prestigious American university, he would have been pleased. Jim, who is planning to go to law school, has many talents: he is a member of the debate club, and editor-in-chief of the school newspaper; he plays the flute, holds numerous winning titles in wrestling, has been on the dean's honor list since his freshman year, and is universally liked as a charming, articulate, caring person. He is an all-American, well-rounded guy. Jim has a dark secret, though: he has not really spoken to his grandparents since he was five, he cannot write to them, and he cannot sign his name.

Jim's grandparents speak no English. Jim's birth name is Cho Dong-In. Jim is a Korean American who can barely speak in Korean. In short, he is a hyphenated American who would have made Teddy Roosevelt happy. In fact, Roosevelt should not have worried in the first place: about a third of incoming college students in early twenty-first 
century America are like Jim (Brecht and Ingold 1998). They "speak American" and their knowledge of the language they were exposed to from birth can range from limited to non-existent. Thirty years ago these people were called semi-speakers (Dorian 1981), and they have also been called incomplete acquirers (Montrul 2002, Polinsky 2006), unbalanced, dominant, or pseudo-bilinguals (Baker and Jones 1998), early bilinguals (Kim et al. 2006), or speakers of "kitchen language __" (fill in the blank). The multiplicity of terms may be, in part, a reflection of the general lack of clarity among linguists about what such speakers know of their home language, and how best to characterize them linguistically. About ten years ago, a term that had been used earlier in Canada (Cummins 2005: 585) to denote this elusive group of speakers made its way to the U.S: heritage speakers. ${ }^{1}$

Two conceptions of heritage language have been proposed; we will refer to them as broad and narrow. The broad conception of heritage language emphasizes possible links between cultural heritage and linguistic heritage. A definition by Fishman (2001: 81) stresses a "particular family relevance" of a language, and Van Deusen-Scholl (2003: 222) defines those who "have been raised with a strong cultural connection to a particular language through family interaction" as language learners (not speakers) "with a heritage motivation". While "heritage motivation" and "family relevance" are important impetuses for learning a language, they are not sufficient to charcterize linguistic

\footnotetext{
${ }^{1}$ While it has gained momentum, the term has also encountered opposition from some researchers and educators who think the term focuses on the past rather than the present and future. Nevertheless it has been used extensively since the first Heritage Conference in 1999 (Peyton et al. 2001).
} 
knowledge proper, and do not provide operational criteria for identifying heritage speakers. Culturally motivated learners who learn their heritage language from scratch as adults are regular second-language speakers, albeit with a different motivation; their learning trajectory sets them apart from speakers like Jim, described above. For broadly defined heritage speakers, the heritage language is equivalent to a second language in terms of linguistic competence, and as a second language it typically begins in the classroom, in adulthood; for speakers like Jim, their heritage language begins in the home, and often stops there, too. While we recognize cultural heritage as an important motivating factor, we would like to underscore the difference between a culturally motivated L2 learner and a true heritage speaker in the narrow sense of the term, the sense to which we now turn.

The best known, and most widely used, definition of heritage speakers under a narrow conception of the term is Valdés's (2000). She refers to heritage speakers as "individuals raised in homes where a language other than English is spoken and who are to some degree bilingual in English and the heritage language."2 Although the original definition is English-centered, any other dominant language can be substituted for English. The crucial criterion is that the heritage language was first in the order of acquisition but was not completely acquired because of the individual's switch to another

\footnotetext{
${ }^{2}$ The definition of a heritage speaker in general and for specific languages continues to be debated. The debate is of particular significance in such languages as Chinese, Arabic, and languages of India and the Philippines, where speakers of multiple languages or dialects are seen as heritage speakers of a single standard language taught for geographic, cultural or other reasons (Mandarin Chinese, Classical Arabic, Hindi, or Tagalog respectively).
} 
dominant language. The other critical component of this definition has to do with identifying continua of proficiencies, reflecting the tremendous variation in heritage language observed by researchers.

As often happens with word magic, the arrival of the name 'heritage speakers' created a new field. Settling on the term helped researchers identify the research questions associated with this group of speakers. In this survey article, we will concentrate on several questions that we consider to be of primary importance:

- What is known about heritage languages and the range of variation among them?

- What is the structure of a heritage language and what does it tell us about human language potential in general?

- Can the degree of maintenance and attrition of a particular heritage language be predicted for a given individual or community? and,

- What pedagogical challenges do heritage languages present?

As the reader will quickly notice, many of the general questions we pose lead us to new questions, still awaiting answers. It is our hope that this article, which is intended to serve as much as a promissory note as an assessment of the emerging field, will stimulate new research seeking to answer the outstanding questions below.

\section{Heritage language "in the wild"}

\subsection{Variation and classification}

Anyone who has even a casual acquaintance with heritage language speakers, be that a language instructor or a second language learner of the language that heritage speakers learned in the home, will be quick to tell you that all of these speakers are different and 
seem to know different things, and that many of them sound native-like. We will address these speakers' often native-like pronunciation in section 3; in this section, we will discuss the apparent range of variation found in heritage populations.

The idea that any given language is subject to speaker variation at every possible level is not new: ask five English speakers to judge the following sentences and you will get five different answers, from completely unacceptable to just fine:

(1) The birds the linguists they commented on the work of studied are very smart.

(2) Which prizes did you wonder how many people would eventually be awarded?

In heritage languages, however, the range of variation is much greater, and it often leads to the suggestion that heritage languages are not systematic or, using a milder version of this claim, do not have any categorical distinctions. We would like to argue that this is not true. The illusion of endless variation comes from our neglecting to look closer and recognize groups within the accepted variation range.

Because of their exposure to the home language throughout childhood and, for some, even into early adulthood, heritage speakers' strongest suit is generally aural comprehension. Their speaking abilities fall within a continuum, from rather fluent speakers, who can sound almost like competent native speakers, to those who can barely speak the home language. The continuum is reminiscent of what has been proposed in creole studies. For creole languages, there usually is not one standard variety of the creole to which most speakers conform, but rather there is a continuum of creole varieties, ranging from the variety closest to the lexifier (the acrolect) to the least lexifier-like (and 
often least socially prestigious) variety, known as the basilect (Bailey 1973, 1974, Bickerton 1973, 1975):

$\begin{array}{llll}\{\text { basilect } & \text { mesolect } & \text { acrolect }\} & \text { lexifer } \\ \leftarrow & \ldots \ldots \ldots & \rightarrow\end{array}$

Although the idea of a creole continuum has been subject to numerous refinements and modifications (see Rickford 1987 for an insightful discussion), the general conception of a scale which accommodates most of the variation remains quite solid. This conception allows researchers to capture variation by measuring a particular variety's distance from the baseline. In heritage language populations, those heritage speakers who can be objectively shown to be near-native, maximally close to a competent (albeit not formally or fully educated) speaker, can be characterized as acrolectal, highproficiency speakers. Those who are maximally removed from native attainment and who show many deviations from the baseline would correspond to basilectal, lowestproficiency speakers. Typically, the access of such lowest-proficiency speakers to the baseline has been restricted to home language (which they often only overhear, cf. Au and Romo 1997), and often they have been isolated from the community in which their home language is dominant (we will refer to such communities as the 'metropoly').

A common profile of such a basilectal speaker would be that of children growing up in the U.S. in a family where the home language is not English; such children hear the home language as spoken by one or both parents, and sometimes by other family 
members or caretakers. Once they go to preschool, their exposure to the home language continues to be limited to home communication, and many such speakers very quickly get into the way of hearing the home language but responding in English (or whatever the dominant language may be). Additionally they may have never learned to read or write in the home language, and if the alphabet is non-Latin, this naturally makes matters even more difficult. By the time they get to college and attend a class in their home language, they may address their instructor as "Aunt Amy" or "Uncle George", and use the familiar form of address or more direct imperatives than are usually expected in formal contexts - forms that they may have picked up in interaction at home while growing up. An acrolectal speaker, on the other hand, is someone who has limited deficiencies in some registers of the baseline language and may even have good awareness of the standard, in addition to the baseline. Overall, the proposed continuum model for heritage languages would be as follows: ${ }^{3}$

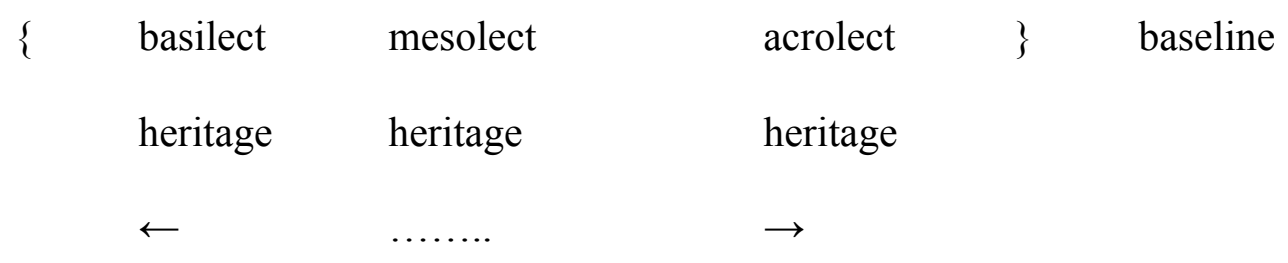

The proposed continuum representation allows us to classify the variation found among heritage speakers in the same way as has been applied to creoles. However, it requires knowledge of the baseline for comparison and an evaluation metric that can be

\footnotetext{
${ }^{3}$ In this survey we focus mainly on basilect and acrolect, but the recognition of finer distinctions on the continuum is, of course, important.
} 
used to assess a speaker's distance from this baseline. In what follows, we will take up these issues in turn.

\subsection{Establishing the baseline}

In the case of an idealized creole continuum, the baseline language is the lexifier-for example, English as spoken in Jamaica for Jamaican Creole, “colonial” French for Seychellois, and so on. But what constitutes the baseline for heritage languages?

The baseline language for a heritage speaker is the language that he or she was exposed to as a child. A common misconception is that a heritage speaker's baseline language is the standard language as promoted by schooling, media, and literature. For instance, a naïve expectation might be that someone who grew up in Orange County, California, speaking Vietnamese at home, would know contemporary standard Vietnamese, which is based on the Northern dialect. In fact, all second-language learning textbooks on Vietnamese reflect this standard, as do the materials for heritage speakers used, for example, in the heritage Vietnamese classes currently offered at UCLA or UCSD.

However, it is the southern dialect of Vietnamese that is spoken by the majority of Vietnamese speakers in Orange County, and which, therefore, is the baseline for their children who grow up exposed to it in the home. Thus it is a mistake to expect those speakers, who have not been through formal schooling in Vietnamese, to have any knowledge of the standard or Northern dialect. Similar mismatches between the baseline and standard language occur for heritage Russian speakers in the U.S., most of whom have had access to the southern varieties of the language (Polinsky 2000) rather than the standard language associated with Russian literature, schools, and media, and which, 
until recently, was valiantly maintained by small numbers of early post-communist émigrés in France or Germany (Zemskaja 2001; see also Polinsky 2003). Likewise, it would be unrealistic to expect a heritage speaker of Spanish in Florida, where Cuban Spanish is the norm, to have even rudimentary knowledge of Iberian Spanish or, closer to home, more standard dialects of Mexican Spanish.

The discrepancy between the baseline and an idealized standard is even more complicated for languages with well-articulated registers, such as Korean or Japanese. Korean has six well-differentiated registers, which vary according to the social distinctions between the speaker and hearer (Sohn 2001: 16, $407 \mathrm{ff}$.). Each register is associated with particular phonological patterns and lexical choices (Kim 2001; Choi 2002). Of those six registers expected of any grown-up competent speaker, heritage speakers of Korean are familiar with one or, at most, two (Kim 2001: 262) — the intimate register (identified as the $-e /-a$ register in the literature on Korean) and possibly familiar register (identified as the - ney register). These two registers are used in the home and are typical of children, but a grown up speaker is of course expected to control the other four registers as well. However, since heritage speakers of Korean have not been instructed in more formal registers it would be counterproductive to expect them to control anything beyond this baseline.

This brief discussion points to a conclusion and an open question. The conclusion is straightforward: since heritage speakers of language L are typically not exposed to the language norm through formal schooling, their baseline is the particular variety of $\mathrm{L}$ that such speakers were exposed to in the home, and should not be identified with the standard language available to fully competent speakers of L. For quite a few languages, 
including mainstream American English, such a standard is often identified by the absence of certain features expressly associated with a particular area or social class (Wolfram and Shilling-Estes 1998: 53-88). Since this standardization is highly conventional, it takes consistent exposure, for example through schooling, to impose the standard on an individual; heritage speakers do not have such exposure in their background.

The outstanding question has to do with the need to establish the baseline for each particular heritage language. Establishing the baseline requires knowledge of demographic patterns (who settled where and when) and a good understanding of dialectal and/or register differentiation in a given language. For some languages, both ingredients may be readily available to the scholar, but for others work on one or both of these would need to be done prior to a serious assessment of the heritage language in question.

This question is also of importance when heritage speakers come to learn their home language in a formal educational setting. The discrepancies between their spoken language and the educated norm taught in the classroom may lead some instructors to discount their knowledge rather than value it. Language instructors tend to look for gaps in knowledge (which are, of course, plentiful in these cases) rather than assign value to the rich and varied linguistic backgrounds that these learners bring with them.

This often unintentional difference in approach to second language learners vs. heritage speakers reminds us of the glass half-full/half-empty metaphor. With second language learners, every small step toward attainment is celebrated and accepted, and the necessary gaps in knowledge are viewed as part of the course. In the assessment of 
heritage speakers, however, the glass is perpetually half-empty: it is hard to ignore what they don't know, that they cannot read or write, that they don't know the standard, and that they do not speak like true native speakers. While the L2 learner's achievement, no matter how limited, is viewed favorably, to some instructors the heritage learner's competence is always suspect, and both instructors and curriculum designers tend to take stock only of their deficiencies. To establish an adequate curriculum for these learners, we need to adopt the "the glass is half full" approach, i.e. a more optimistic outlook based on how much heritage speakers already know.

The problem is exacerbated in cases where language instructors are biased against the language variety that served as the home language. In their study of the attitudes of members of various Spanish language and literature departments in the U.S. to academic Spanish as spoken by Spaniards, Mexicans, Latin Americans, and Chicanos, Valdés and her co-authors (in press) discovered that educators' views on literacy and prestige dialects resulted in prejudices favoring certain varieties of academic Spanish and against other varieties.

\subsection{Classifying heritage speakers}

Let's assume that we have established the baseline for a given heritage language. Even without observing a particular speaker, is it possible to get a quick sense of how close his or her language is to the baseline? Surprisingly, the answer is a partial yes. Based on linguistic research on incomplete acquisition and near-native attainment, including the work done by one of the present authors, several diagnostics can be proposed to establish a speaker's proximity to the baseline. One of the most important ones seems to be speech rate. 
Speech rate is the word-per-minute output in spontaneous production-as evaluated, for example, in the description of a picture set. ${ }^{4}$ The speaker is asked to describe one set of pictures in her heritage language and another set in English; doing so provides a standard of comparison for assessing individual variation in speech rate. Results show that a heritage speaker's speech rate may be as low as $30 \%$ of the average speech rate for the baseline control, but on the other hand, some heritage speakers come very close to the baseline rate (Kagan and Friedman 2004).

The relevance of speech rate is attested by a recent study of gender restructuring in heritage Russian (Polinsky in press-a), which showed that heritage speakers fell into two distinct groups: (A) those who maintained the baseline three-gender system of noun classification, with various adjustments, and (B) those who radically reanalyzed the baseline system as a two-gender system. The latter tendency was strongly correlated with a lower speech rate. Figure 1 shows the results for average speech rate in monolingual baseline Russian, monolingual English, and the speech rates in English and Russian for two heritage speakers, chosen to represent the highest (AR) and lowest (BL) speech rate in the subject pool.

\footnotetext{
${ }^{4}$ We have been using frog story pictures (Berman and Slobin 1993); these have been successfully used in many studies involving narratives, with adult and child-language alike, and as a result, a large body of data, including statistics on several languages, has been made available by these studies.
} 


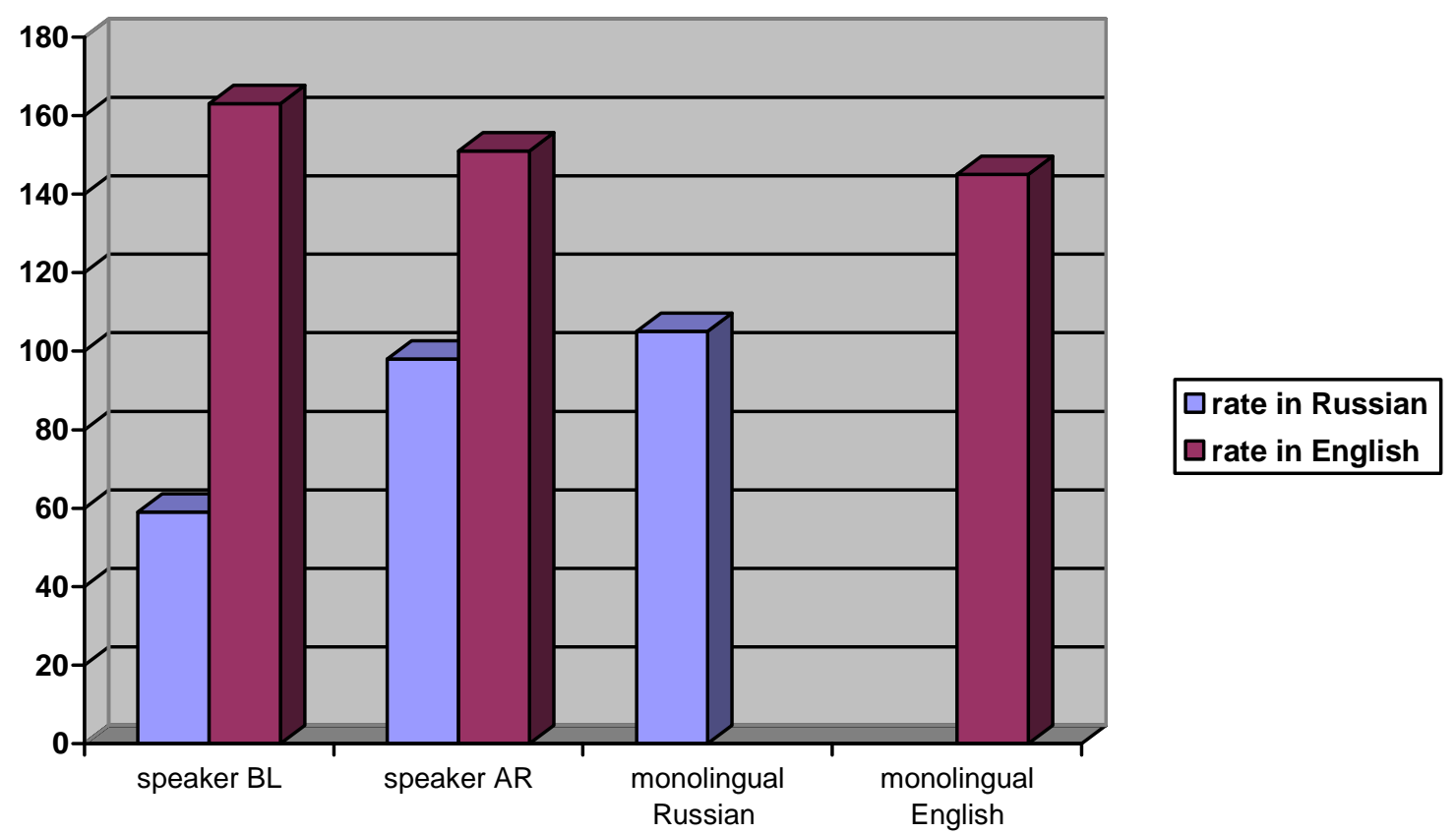

Figure 1. Average speech rate in heritage Russian, baseline Russian, English spoken by American Russians, and monolingual English (frog story narrative, words per minute)

Besides adding more evidence to our earlier claim concerning the tremendous variation in heritage speech, the data in figure 2 also show the correlation between speech rate and retention of the three-gender system of baseline Russian in heritage speakers: a threegender system is correlated with a higher speech rate, while a two-gender system is correlated with a lower speech rate. The motivation behind this correlation is rather straightforward. Lower proficiency speakers, who presumably represent the basilect, have more difficulty in accessing lexical items, which slows down their speech. As we will show below, knowledge of lexical items and grammatical knowledge are also correlated. Not surprisingly, problems with lexical access are accompanied by difficulty constructing phrases and clauses; the spontaneous speech is punctuated by pauses, repetitions, and false starts. All of this has an immediate effect on the speech rate. 


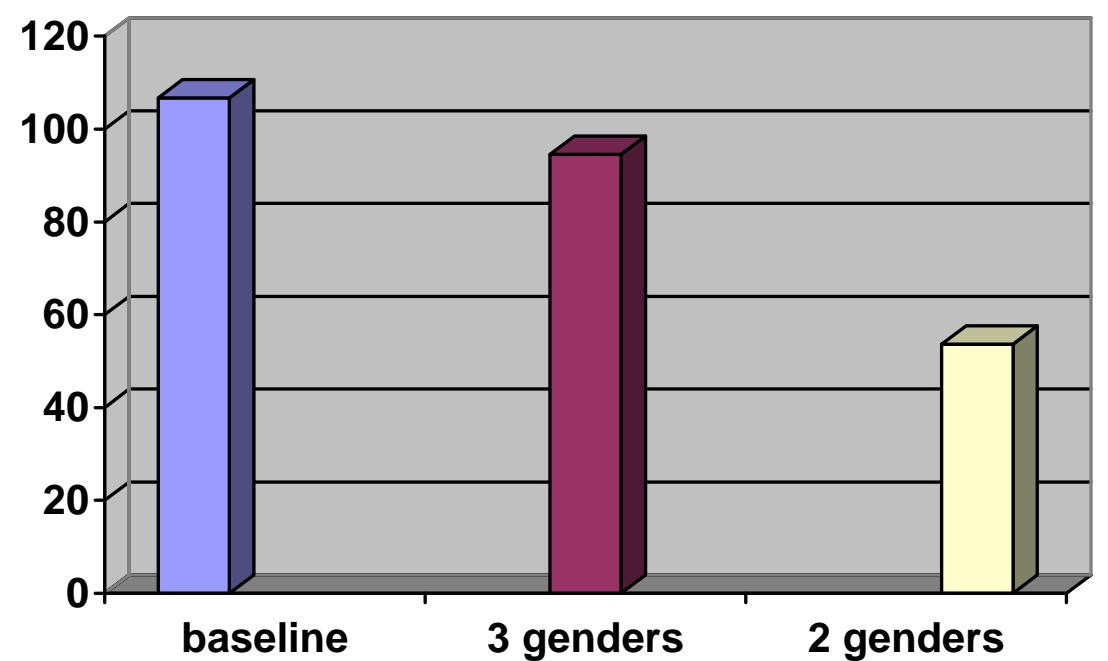

Figure 2. Rate of speech (words/min) in baseline controls, speakers who maintained the three-gender system, and speakers who switched to a two-gender system for Russian nouns.

Although correlations such as the one shown in figure 2 need to be tested with other grammatical phenomena and different heritage languages, they offer a promise of relatively simple diagnostics of language proficiency which can be used both in the lab and in the classroom.

Speech rate may be a promising method of classification, but it could be difficult to determine for the lowest-proficiency heritage speakers, who may be reluctant to produce any language whatsoever. Another diagnostic of proficiency in heritage languages that may be even more powerful is lexical proficiency. In earlier studies (Polinsky 1997, 2000, 2006) we have observed a strong correlation between a speaker's knowledge of lexical items, measured in terms of a basic word list (about two hundred items), and the speaker's control of grammatical phenomena such as agreement, case marking, aspectual and temporal marking, and use of subordinate clauses, with grammatical knowledge measured by deviations from the baseline in spontaneous speech (Polinsky 1997) and, in later studies, by answers to forced-choice judgments (Polinsky 
2005). The correlation between the levels of grammatical and lexical knowledge was supported by results for several heritage languages, including Russian, Polish, Armenian, Korean, and Lithuanian (see also Lee 2001, Godson 2003). This correlation is not exclusive to heritage language competence; it has also been proposed for early child language (Bates et al. 1994; Thal et al. 1996, 1997; Fenson et al. 2000). If structural attrition and lexical proficiency are correlated, lexical proficiency scores, which are relatively easy to obtain, can serve as a basis for the characterization and ranking of incomplete learners in terms of the proposed continuum model.

Another good diagnostic of heritage language proficiency relates to the manner and length of exposure to the baseline. These two characteristics seem interrelated in ways which may not yet be fully understood. With respect to the manner of exposure, it is natural to expect that speakers who grew up surrounded by the baseline language in the metropoly should differ somehow from those who grew up in an immigrant community in the U.S. or any other country where a different language is dominant. The exposure to language in the metropoly is inevitably greater than that in immigrant communities, so one would expect a heritage speaker who spent her first five years of life in Korea to have an advantage over an American-born Korean heritage speaker. Au and Oh (2005) found that speaking the majority language before age five seems to put linguistic minority children at a small, but measurable, risk for poorer heritage language skills during adolescence. Likewise, the length of exposure to the baseline should also matter, since the longer the exposure to the baseline, the greater the baseline input for the heritage speaker. 
Preliminary results show that the effects of length and manner of exposure are not easily separable. The only group that seems to have a distinct language advantage are heritage speakers who grew up in the metropoly and had exposure to the baseline language at least until the end of the critical period. All other groups are more or less indistinguishable; crucially, exposure to schooling in the heritage language after immigration does not seem to have any serious effect, as shown by preliminary studies of Korean Sunday schools (Kwon and Polinsky 2005) and Chinese Sunday schools (Wang 1996, Xiao 2006, Weger-Guntharp 2006).

Finally, the heritage speaker's parents have also been found to have an effect on language maintenance by heritage speakers. Au and Oh (2005) demonstrate that the language spoken by parents in the home, as well as parents' attitudes toward the home language and culture (e.g., instilling ethnic pride, discussing ethnic history and identity, encouraging children to learn and practice cultural traditions and values) are correlated with the children's later abilities in the home language.

\section{Heritage speakers' language knowledge}

In this section, we will concentrate mainly on the lowest proficiency, basilectal speakers, simply because it is their language that shows the most striking deviations from the baseline. According to the diagnostic measures described above, basilectal speakers are speakers who grew up with limited or early interrupted exposure to the home language, and consist of "overhearers" (Au et al. 2002, Oh et al. 2003), who heard the home language in the background but never responded in it and were not addressed in it consistently, and bilinguals who switched to the dominant language as early as preschool (Polinsky 1997, Montrul 2004a). In terms of speech rate, such speakers typically fall in 
the range of a third to one-half of the speech rate of the baseline (Polinsky in press-a). Finally, such speakers seem to have a lexical proficiency of about $70 \%$, using the basic vocabulary technique (Polinsky 1997). Of course, the group of basilectal heritage speakers may not be as homogenous as we present it here; the impression of homogeneity may simply be the artifact of our limited knowledge of this group.

Assessing the linguistic knowledge of basilectal speakers is a challenging taskmany of them can barely speak in the heritage language, and persuading them to produce spontaneous speech, even under the controlled conditions of narrative elicitations, is not easy (Polinsky 2006; Silva-Corvalan 1994). Aside from this rather torturous spontaneous production, the bulk of the data on their language knowledge comes from grammatical judgment tasks; such data are now available for Spanish (Toribio 2001, Montrul 2002, 2004a, b, 2006, , Zapata et al. 2005, Roca 2000), Greek and Italian (Tsimpli et al. 2003, 2004, Sorace 2004), Russian (Polinsky 2005, 2006, in press-a, b), and Korean (Kim et al. 2006).

\subsection{Phonetics and phonology}

In the sound system of the baseline language, the general impression is that even basilectal heritage speakers sound native-like, and this gives them a distinct advantage in re-learning the home language when exposed to it in the classroom, for instance in college (Au and Romo 1997). This phonetic advantage is often cited as one of the main reasons for placing heritage and second language learners on different tracks in the classroom (Peyton et al. 2001). On the other hand, anecdotal evidence that heritage speakers have a slight 'accent' also abounds: competent speakers of the baseline often 
comment that heritage speakers sound 'funny', 'off', and not like 'real' speakers of the language.

It is well known that bilingual speakers have different phonetic representations than monolinguals (Caramazza et al. 1974, Bullock et al. 2004, Sundara et al. 2006), so the presence of a heritage 'accent' should not come as a total surprise. However, there is emerging evidence that heritage speakers differ from more balanced bilinguals as well. For example, an instrumental study of vocalism in heritage Western Armenian (Godson 2003, 2004) showed that heritage speakers differed from both Armenian-dominant bilinguals and monolingual baseline speakers. The difference could not be attributed solely to transfer from English: English seemed to play a role only for those vowels that are already close to English (namely, /i/,/e/). The heritage speakers' other vowels, and particularly /o/ and /u/, were quite distinct from their English counterparts and from the respective vowels in the bilingual system. While the reasons for such differentiation remain unclear, Godson's results clearly show that the heritage accent is a measurable reality. Studies of both consonantal and vocalic systems in other heritage languages are desirable and may reveal further regularities.

While instrumental studies targeting the phonetics of heritage speech are badly needed, virtually nothing is known about the nature of phonological representations in heritage speakers. The lack of studies is due, in part, to the fact that we are dealing with an emerging field, but is also likely due to the fact that heritage speakers generally sound so native-like — one could easily imagine that there would be no differences in phonological representations between the heritage language and the baseline, although that remains to be shown. 


\subsection{Morphological categories}

Turning to morphology, basilectal heritage speakers show an across-the-board over-regularization in morphological paradigms, with the elimination of irregular and infrequent forms (see Seliger and Vago 1991 for a number of languages; Silva-Corvalan 1994; Anderson 2001; Montrul 2002, 2004a for Spanish; Halmari 1998, 2005 for Finnish; Levine 2000 for Yiddish; Polinsky 2000, 2006, in press-a, c for Russian; Caruso 2004 for Italian; Choi 2002 for Korean; Dutkova 1998 for Czech; Cozens 2003 for Polish). Complicating the picture somewhat is the fact that the bulk of morphological leveling and over-generalization that has been documented occurs in heritage languages with interference from English, which itself does not show rich morphology. The few studies of incomplete acquisition under the dominance of other languages, however, show that over-regularization happens nevertheless, thus suggesting that transfer from the dominant language is not the complete answer (cf. Backus 1996, 1999 for the incomplete acquisition of Turkish in Holland, or Leisio 2001 for the incomplete acquisition of Russian in Finland). ${ }^{5}$ Over-regularization is particularly apparent in verb forms, simply because most languages have a larger variety of verb paradigms to start with. However, it is also present in nominal and pronominal declensions and other morphological subsystems.

Two observations are in order here. First, while formal over-regularization is visible and often occupies the center of researchers' attention, it is also important not to

\footnotetext{
${ }^{5}$ Superficially, it may seem that there are many more studies of what may be incomplete acquisition in bilingual communities, but such studies often avoid the question of change in the "home" language and focus on such phenomena as code-switching.
} 
lose sight of over-regularization in interpretation. The underlying principle of such overregularization is the elimination of polysemy. For instance, Montrul (2002) shows that heritage Spanish speakers do not use achievement verbs in the imperfect. Achievement verbs typically describe an event that has an endpoint; the imperfect tense is often, although not always, associated with the absence of such an end point. It seems that heritage speakers may over-generalize the semantics of the imperfect to the extent that they never use it to indicate completed action. Language instructors are familiar with heritage speakers questioning whether imperfect verbs can even be used in the past tense because the action they express does not have an end point. Another observation concerning the reanalysis of tense and aspect in heritage speakers has to do with the avoidance of the past tense with stative verbs (examples of stative verbs include verbs expressing feelings: 'like', 'hate’, 'love', 'be sad', etc.) (Montrul 2002 for Spanish; Polinsky 2006 for Russian). The past tense can easily be generalized as locating an event in time prior to the reference point; meanwhile, stative verbs are often associated with the absence of temporal limits, with the same result as described above for imperfect verbs.

In addition to overgeneralizing in both form and meaning, heritage speakers are also extremely good at maintaining fossilized forms of high-frequency items - for instance, count forms (even in the absence of the full-fledged nominal paradigm), frozen adpositional (pre- and postpositional) phrases referring to time or location ('on Monday', 'at home', 'with me'), or occasional polite imperatives. Such fossilized forms or 'chunks' may make it seem that a heritage speaker controls more morphology than she actually knows, and they certainly add to the impression of tremendous variation among heritage speakers. If our knowledge of heritage languages remains confined to heritage speakers' 
production, especially spontaneous production, it is inevitable that such fossilizations will cloud the issues in this way. Only systematic perception experiments will allow us to separate fossilized chunks from the speakers' more productive knowledge of grammar.

The presence of fossilized chunks in heritage speech raises a more general question regarding the role of frequency in heritage language grammar. What if all that heritage speakers know is just a combination of high frequency items that were present in the input? The answer to this question is important not only for our understanding of heritage languages, but also for the ongoing debate on the role played by positive and negative evidence in language acquisition. Few people, if any, doubt that frequency of input is important to acquisition; however, it is not clear whether frequency plays a direct or more mediated role in language learning. In our study of heritage speakers' knowledge of lexical classes (parts of speech), we addressed this question from the standpoint of the interaction between frequency and structured grammar (Polinsky 2005). Heritage speakers showed a strong differentiation of lexical items of identical frequency based on their lexical class: they had a much better control of verbs over nouns and adjectives of the same frequency. Within each lexical class, more frequent items were accessed faster than lower frequency items, but the differentiation across lexical classes was much more pronounced. While studies such as this are awaiting replication, we can hypothesize that frequency cannot be all there is to incomplete acquisition.

\subsection{Syntactic structures}

The syntactic characteristics of basilectal heritage language are still poorly understood but some generalizations have started to emerge, and we will focus on those here. As in the discussion of other language subsystems, we would like to start with methodological 
observations. Generally, linguistic research in syntax relies heavily on speakers' intuitions as elicited in the form of grammaticality judgments. The reliance on intuitions has received its fair share of criticism from linguists working on uninterrupted acquisition and completely acquired languages; with respect to heritage language, however, judgments are particularly hard to elicit and assess. It is quite striking that lowproficiency heritage speakers perform at chance on staple grammaticality judgments that linguists are so good at using, for example, with respect to so-called 'binding' phenomena, that is, grammatical constraints on the distribution of reciprocals, reflexives, pronouns and proper names ${ }^{6}$ (see Polinsky 1997, 2006 for data on heritage Russian).

We are not sure what may motivate low-proficiency speakers' reluctance to produce grammaticality judgments, but at this stage we would like to offer a cautionary note regarding the actual use of forced choice with low-proficiency heritage speakers. Since heritage speakers are often very limited in what they can produce spontaneously, the potential for observation of their naturally occurring speech is also limited. At the level of methodology, this suggests that we should rely on the standard language tasks used with populations whose speaking ability is limited (e.g. child speakers, aphasics);

\footnotetext{
${ }^{6}$ These constraints, which together constitute the Binding Theory in generative grammar, are responsible for the failure of the pronoun and the proper name to refer to the same person in sentences like 'John likes him'; on the other hand, when 'him' is replaced by a reflexive, 'John' and 'himself' must be coreferential: 'John likes himself'. The robust nature of competent speakers' judgments about sentences like these means that the Binding Theory is a useful diagnostic tool for a whole host of syntactic phenomena; that heritage speakers should perform no better than chance on these judgment tasks therefore presents a new challenge to the traditional syntactician.
} 
such tasks include picture naming, picture-utterance associations, or simple cross-modal priming. In our experience, this methodology has been most effective in establishing what heritage speakers actually know, but it is, of course, painstaking and slow. In the rest of this subsection, we will focus on several recurrent features of heritage language grammars. Given the simplification of morphology described above, it is not surprising that heritage languages show a much smaller range of morphological case distinctions than the baseline; this has been observed for a wide range of heritage languages (Seliger and Vago 1991; Polinsky 1996; Halmari 1998). One of the striking properties of case reanalysis in heritage systems is the use of an unmarked case (nominative, absolutive) as the generalized case, including as the case used with adpositions. For instance, in heritage Kabardian, complements of postpositions appear in the marked (definite) absolutive case (5a), while in the baseline postpositions require the generalized oblique $(5 b):^{7}$

(5) a. bostexə-r pajə

dress-ABS.DEF for

b. bostexe-m pajə

dress-OBL for

'for the dress'

\footnotetext{
${ }^{7}$ Note also pronunciation differences between the heritage form and the baseline form.
} 
Another tendency, especially with baseline languages that have an articulated system of oblique cases, is for the heritage language to have one generalized oblique case. In heritage Russian, for instance, in the plural, this case is the prepositional in -ax, which replaces the other oblique cases - compare the examples in (6). Intriguingly, a similar overgeneralization of the prepositional case is observed in Russian child language (Gvozdev 1961: 334) and in non-standard dialects of Russian.

(6) Heritage vs. baseline Russian: oblique case marking in the plural

\begin{tabular}{|c|c|c|c|}
\hline & Heritage & Baseline & \\
\hline \multirow[t]{2}{*}{ a. } & bez rukav-ax & bez rukav-ov & 'without sleeves' \\
\hline & without sleeve-PRP.PL & without sleeve-GEN.PL & \\
\hline \multirow[t]{2}{*}{ b. } & mnogo stakan-ax & mnogo stakan-ov & 'many glasses' \\
\hline & many glass-PRP.PL & many glass-GEN.PL & \\
\hline \multirow[t]{2}{*}{ c. } & za skamejk-ax & za skamejk-ami & 'behind the benches' \\
\hline & behind bench-PRP.PL & behind bench-INSTR.PL & \\
\hline \multirow[t]{2}{*}{ d. } & dlja detj-ax & dlja det-ej & 'for children' \\
\hline & For children-PRP.PL & for children-DAT.PL & \\
\hline
\end{tabular}

In the baseline language, case encodes relations between the case-assigning head and its dependent; once morphological marking of case is reduced or eliminated, these relations between the assigner and its dependent must be expressed in some other way. The potential compensatory strategies for expressing these relations after the loss of morphological case include agreement and word order. Since agreement typically requires sophisticated morphology, which heritage language systems do not have, fixed word order thus becomes a staple feature of heritage language grammars. As a result, in languages where discontinuous expressions are found, this feature is lost in the heritage 
variety. For instance, in Korean it is common for a quantifier (a word like 'all' or 'many') to appear discontinuously, away from its associated noun phrase; this phenomenon is known as 'quantifier float' (Gerdts 1987, Miyagawa 2006). ${ }^{8}$ Yet heritage Korean speakers invariably produce the quantifier adjacent to the noun, and if asked to judge expressions with floated quantifiers they generally hesitate or even find them ungrammatical.

In addition, flexible word order languages lose their general ability to scramble (the ability of lexical items to move from their base positions, resulting in apparent flexibility of ordering with respect to subject, verb and object); for instance, another feature of heritage Korean is lack of scrambling from SOV to OSV word order, a feature observed in the baseline, hence indicating the freezing of surface word order (Kwon and Polinsky 2005). Notably, heritage speakers of those baseline languages that can invert subject and verb in certain constructions (such as Spanish, Finnish, and Russian) typically do not show the expected verb-subject order (Silva-Corvalan 1994; Sanchez 1983; Halmari 1997; Isurin and Ivanova-Sullivan 2007).

While it would be tempting to motivate the rigid word order found in heritage grammars by universal tendencies in language encoding, we do not think that the time for such a conclusion has arrived. As mentioned above, most of our data on heritage languages come from speakers whose dominant language is English. With its own shallow morphology and rather rigid word order, it may simply be that English acts as a

\footnotetext{
${ }^{8}$ Quantifier float is present in English as well, for example in (ii), where each 'floats away' from its host noun children:
}

(i) The clown gave each child two balloons

(ii) The clown gave the children two balloons each 
source of transfer (cf. Ionin 2007). If so, data on heritage languages spoken in communities where another language is dominant are needed to decide between the universalist explanation and the transfer explanation of word order effects observed in low-proficiency heritage speakers.

In addition to the more surface-level phenomena related to case marking and word order, heritage speakers also have difficulty maintaining syntactic dependencies pertaining to a more abstract level of syntactic representation, what was traditionally termed 'Deep Structure'. An example might be so-called 'long-distance dependencies' ${ }^{9}$ These configurations involve a relationship between two syntactic positions across a stretch of lexical material, where the lexical item in one of these positions (a pronoun, for example) is not on its own sufficient to determine its reference (say, the particular person that it picks out), and is instead dependent upon the content of a noun phrase elsewhere in the sentence. In such a case, the more fully articulated noun phrase is termed the 'antecedent' of the underspecified item, and the two terms are conventionally marked with the same subscript index to indicate that they refer to the same individual. For example, a lexically specified noun phrase can serve as the antecedent of a pronoun (including a null pronoun) (7a), a reflexive anaphor (7b), or even an element that is not pronounced at all, but is nevertheless present in syntax as a 'gap' or null element (7c, d).

(7) a. A reporter asked the senator ${ }_{i}$ what she ${ }_{i}$ hoped to accomplish with the new bill.

b. A reporter asked the senator ${ }_{i}$ about herself $_{\mathrm{i}}$.

\footnotetext{
${ }^{9}$ This seems to apply both in production and comprehension, although data on comprehension are extremely scarce.
} 
c. A reporter asked the senator ${ }_{i}$ at the press conference ${ }_{i}$ to elaborate on the new proposal.

d. A reporter interviewed the senator ${ }_{i}$ [that everyone admired

Without going too much into detail, we would like to make a couple observations here. First, heritage speakers have significant difficulties producing null elements. For structures such as $(7 \mathrm{c}, \mathrm{d})$, a typical strategy might involve the use of a pronoun instead of a gap. Given that verbal morphology is not fully represented in heritage speech, this often leads to an impression that heritage speakers have difficulty with embeddings. In addition, the absence of null elements creates an impression of extreme redundancy, with pronouns commonly appearing where the baseline language does not show any. As an illustration, consider the following excerpt from a frog story (heritage Russian speaker, 23 y.o., interrupted at about 5$):^{10}$

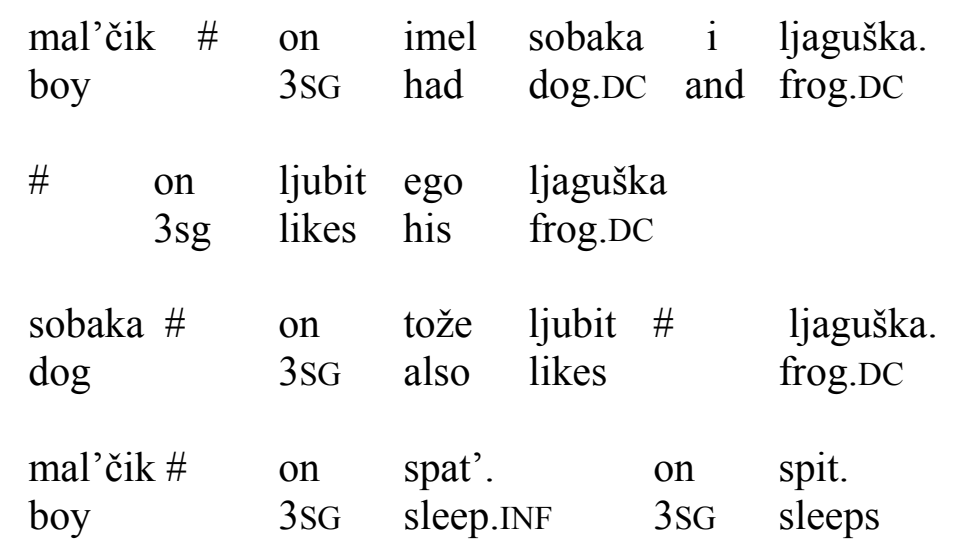
sobaka tože spal, ljaguška vyxodit iz \# jar \# i on uxodil.

${ }^{10}$ Special symbols: code switching is italicized, pauses are indicated by \#; DC - default case, INF-infinitive. 


$\begin{array}{lllll}\text { dog } & \text { also slept } & \text { frog } & \text { comes_out of } & \text { and 3SG was_leaving } \\ \text { on } & \text { uxodil } & \text { iz } & \text { ix dom } & \text { sovsem } \\ \text { 3SG } & \text { was_leaving } & \text { from } & \text { [their house].DC } & \text { completely }\end{array}$

The heritage speaker's use of pronouns therefore amounts to the following non-native sounding sentences in English (and makes the same impression of non-nativeness in Russian):

'The boy HE had a dog and a frog. The dog HE also likes the frog. The boy HE slept."

A more natural translation of the intended story (and a corresponding narration in Russian that could be expected of a full Russian speaker) would be: 'The boy had a dog and a frog. The boy and the dog liked their frog. Once when the boy and the dog were asleep, the frog got out of the jar where it lived and left the house for good.'

Somewhat related to the avoidance of null elements is the difficulty heritage speakers experience with reflexivization. While baseline Russian has standard possessive reflexives, the heritage speaker in (8) does not use them in referring to the frog or the house (that is, the speaker says 'his frog', while a full Russian speaker would be expected to use a special pronoun that means 'one's own', something like 'self's frog').

Spontaneous production and judgment tasks have confirmed this failure to use possessive reflexives, but systematic experimental work is needed to determine the extent to which heritage speakers have difficulty with long-distance dependencies and why. 


\section{Heritage learners in the classroom}

While we focused above on heritage speakers for the purposes of linguistic research, for pedagogical purposes we will focus on heritage learners, namely heritage speakers who wish to regain, maintain or improve their home language through classroom instruction.

The challenge for the teaching profession is to find pedagogical solutions relating to heritage learners based on current linguistic research, a task that clearly has additional practical significance. Otherwise, many heritage learners will continue falling through the proverbial cracks and missing their chance to re-gain proficiency in the home language, as found in a case study described by Wiley (in press). Wiley analyzes the case of a speaker raised in Taiwan until the age of five, when he was brought to the United States and rapidly acquired English. He spoke both Taiwanese and some Mandarin, although with a Taiwanese accent, and when he enrolled in Chinese classes while in college, he failed to advance his knowledge of Mandarin because no course took into account his background and his Taiwanese accent was looked down upon by his instructors. Wiley writes, "Had the course been designed to take into account the background and needs of 'dialect' speakers, his regional 'Taiwanese' accent in Mandarin might not have been treated in a stigmatizing way", and the heritage Chinese speaker would not despair at (re)learning the language. We can substitute another language for Chinese, but the story of frustrated language study will remain the same for very many heritage speakers.

As seen in Wiley's case study, the differences between a heritage learner's home language and the form of the language taught in the classroom are often significant, and can severely hinder a heritage learner's attempts to improve his knowledge of the 
language in a classroom setting. While it is not realistic to expect each home language to be taught separately and with its own course materials, by identifying such mismatches between home language and the standard or other variety of the language taught in the language course, instructors can better accommodate heritage learners and help them achieve their desired language goals.

Among the other challenges of heritage language classroom instruction are the assessment of heritage learners' abilities and curriculum development. We will offer preliminary suggestions with respect to these challenges below.

\subsection{Correlating the heritage language continuum with existing}

\section{classifications}

To better assist language learning specialists to utilize the theoretical results described above, we will now correlate the groupings found by researchers of two wellstudied heritage language groups - - heritage Spanish and heritage Russian speakers - to the heritage language-continuum model proposed herein. In addition, we will propose correlations between the groupings proposed herein and the ratings of L2 abilities used in academia (American Council on the Teaching of Foreign Languages, ACTFL, 1999) ${ }^{11}$ and by U.S. government agencies (Interagency Round Table, ILR). ${ }^{12}$

In her study of heritage Spanish speakers, Valdés (2001) distinguishes between three groups of heritage language students. First, she identifies a group of Englishdominant, third- or fourth-generation U.S.-born Hispanic students who have limited

\footnotetext{
${ }^{11}$ http://www.sil.org/lingualinks/languagelearning/OtherResources/ACTFLProficiencyGui delines/contents.htm

${ }^{12}$ http://www.utm.edu/staff/globeg/ilrhome.shtml.
} 
speaking skills and no literacy in Spanish, all of whom are the least proficient in heritage Spanish; this group consists of basilectal speakers. The second group she identifies consists of first- or second-generation bilinguals who possess different degrees of proficiency in English and Spanish; these students can be expected to display characteristics of basilectal and mesolectal speakers. Her third group consists of recent immigrants to the United States from a Spanish-dominant metropoly and who are Spanish-dominant; we hypothesize that most members of this group would correspond to acrolectal speakers.

Three groups have also been identified among heritage Russian learners (Kagan and Dillon 2001, Kagan 2005). Group 1, the most proficient group, comprises students who graduated from high school in Russia or a former republic of the Soviet Union, and who have a fully developed grammatical system, a native range of vocabulary, and inside familiarity with Russian culture. Group 2 consists of students who attended school in a Russian-speaking country for five-to-seven years (an approximate equivalent of American junior high school) and whose language development in their teenage years was interrupted by emigration. Heritage learners from Groups 1 and 2 are the closest to native speakers in grammatical accuracy and breadth of vocabulary; their speech rate is typically quite high, and their lexical knowledge is around $90-95 \%$ on the basic vocabulary test (Polinsky 1997, 2006). These learners correspond to acrolectal speakers discussed above. Group 3, the members of which can be characterized as 'incomplete acquirers' and 'forgetters' (Polinsky 2000), consists of two main subgroups: (a) students who attended elementary school in a Russian-speaking country, and (b) students who emigrated as preschoolers or were born in the United States to Russian-speaking parents, 
and who have been educated entirely in English. These speakers would be classified as basilectal speakers under the system we propose.

Although designed for the assessment of foreign language learners rather than heritage language learners, the ACTFL and ILR ratings may also be roughly correlated to the model of heritage language proposed herein. The ACTFL ratings distinguish between Novice, Intermediate, Advanced and Superior competencies, with Novice, Intermediate and Advanced competencies divided into three sublevels (low, mid, and high), and the ILR system uses a numerical scale from "0", for speakers with no knowledge of the language, to "5", for speakers with the ability of educated native speakers. Comparing these systems to the abilities of basilectal, mesolectal, and acrolectal learners, we have arrived at the general correlations shown in Table 1.

$\underline{\text { Heritage language model }} \underline{\text { ACTFL }} \underline{\text { ILR }}$

Basilectal speakers Intermediate Low/Mid 1: elementary proficiency

Mesolectal speakers Intermediate High $\quad 1+$ : elementary proficiency plus

Advanced Low/Mid 2: limited working proficiency

Acrolectal speakers Advanced High 2+: limited working proficiency, plus

Acrolectal speakers $\quad$ Superior $\quad 3-5$ : general proficiency, advanced native speakers proficiency, functionally native proficiency 
Table 1. Correspondences between heritage language continuum model and ACTFL and ILR ratings (after NVTC 2006)

\subsection{Assessment challenges}

Accurate assessment of a heritage learner's language ability is essential to placing the learner in a suitable language course, measuring the learner's language achievement, and predicting the learner's achievable proficiency in the language.

Placement tests are of particular interest to language instructors who either have separate tracks for foreign language learners and heritage language learners, or use a differentiated approach in a mixed class (Carreira 2004). However, since foreign language placement tests are typically textbook-based, such tests are not suitable for placing heritage learners, whose language knowledge was not acquired from a textbook. As a result, placement of heritage learners according to the results of such placement tests often results in frustration and dissatisfaction for learner and instructor alike.

To better determine the appropriate placement of heritage learners, a threecomponent testing procedure has previously been suggested, consisting of (i) an oral test loosely based upon the ACTFL oral proficiency interview; (ii) a short essay (if the learner is literate in the heritage language); and (iii) a biographic questionnaire (Kagan 2005). Each component may provide information on a separate aspect of the heritage learners' knowledge; the oral interview provides information on spoken and aural proficiencies, the essay demonstrates the degree of literacy, and the biographic questionnaire provides information about language use in the home and the amount of input and output. The results of self-evaluations of language competencies may also be useful as an assessment 
device. Typically, heritage learners are best at listening, followed by speaking, reading and writing. Figure 3 shows the preliminary results of a survey currently being conducted at UCLA in which heritage learners are asked to assess their language ability. ${ }^{13}$

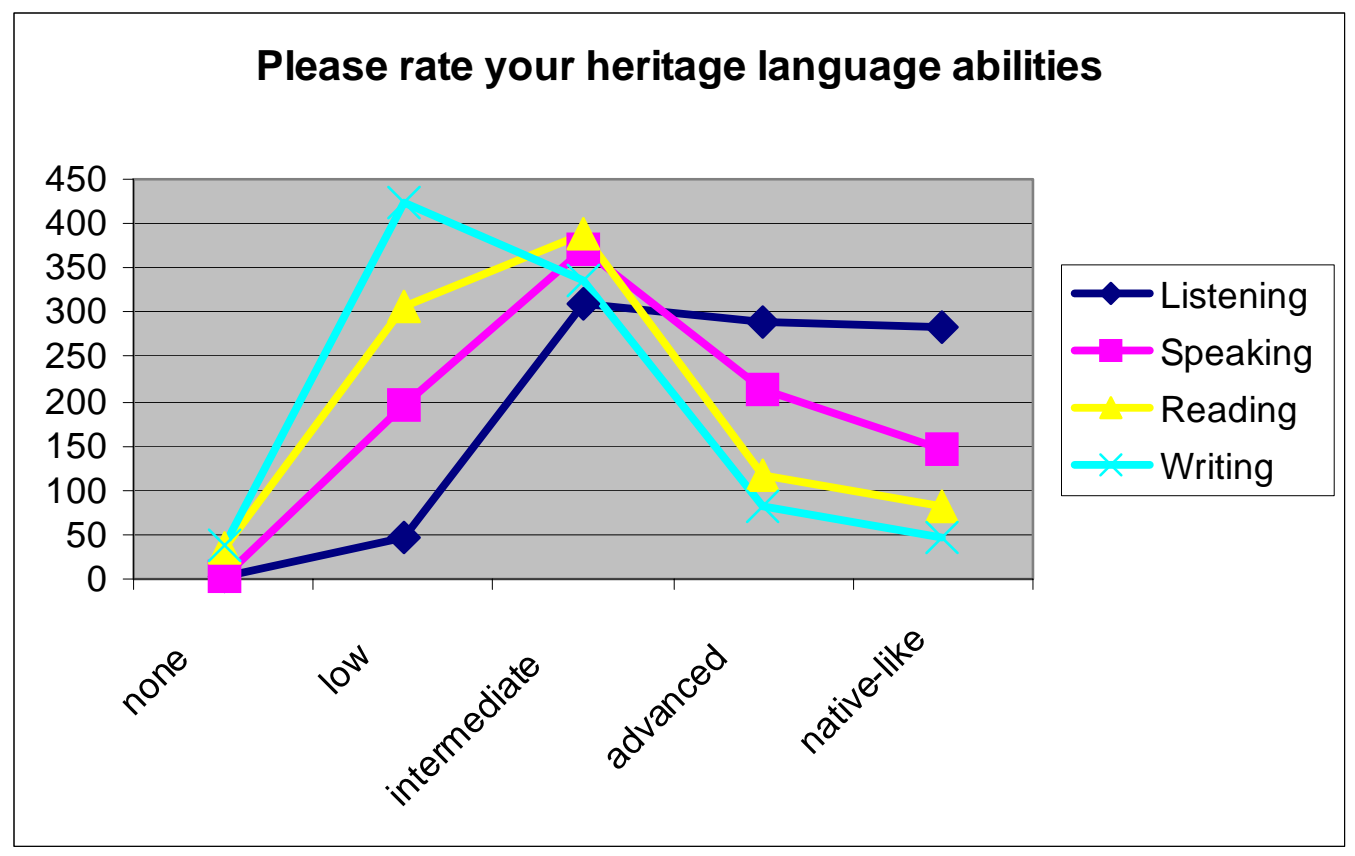

Figure 3. Self-reporting of language ability in the heritage language (data from an ongoing study conducted at UCLA).

As practice shows, the three-component placement procedure is viable, but a more sophisticated testing procedure based on linguistic research may also be suggested. As discussed above, the correlation between a heritage speaker's levels of grammatical and lexical knowledge indicates that a lexical proficiency test may be a reliable

13 The data has been obtained from an ongoing survey of heritage learners conducted by the Title VI National Heritage Language Resource Center. Funding for the study provided by the US Department of Education Title VI grant \# P229A060008. 
diagnostic for determining a heritage learner's proficiency, and one that could be performed quickly and without elaborate testing procedures. Combining such a test with an oral interview and a biographic questionnaire may constitute an improvement to the three-component evaluation described above.

\subsection{Developing a heritage-specific curriculum}

Although a substantial amount of work has been done on the determinants of successful second-language acquisition, much less is known about the particular factors that determine a heritage learner's success or failure in her attempts to study her home language in the classroom. Most existing curricula for heritage learners are adapted from those designed for foreign language teaching, by increasing either the pace or the amount of material to be covered. However, to best meet the needs of heritage learners, a differentiated, learner-centered approach may be required (Carreira 2004).

Valdés (1997), for example, sees the goals of instruction for Spanish heritage speakers as language maintenance, expansion of the bilingual range, development of literacy skills, and acquisition of a prestige variety, standard dialect or literary norm. Similar goals are typically set by other heritage language programs as well. However, unlike instruction in foreign languages, heritage language instruction is not yet viewed as a multi-year sequence with clearly defined goals, a separate curriculum, and measurable outcomes. There is a need for a matrix that could serve as the foundation for a program for heritage language learners (Kagan and Dillon 2003: 100). But as Valdés aptly notes, the teaching of heritage language learners continues to lack a theoretical underpinning because "theories that can directly support their teaching" have not yet been developed (1995: 308). Pedagogical theory relating to the instruction of heritage language learners 
cannot be formulated without language-specific research, like that referred to in this paper, to identify those features of heritage languages that tend to be particularly fossilized or underdeveloped. Heritage language ability-specific research is also necessary, because, as we have attempted to demonstrate, the grammars of low- and highproficiency heritage speakers differ greatly, as do the corresponding pedagogical needs.

At the same time, language educators need to engage in a longitudinal study of pedagogical methodologies and outcomes to determine what works and what does not work in the classroom instruction of heritage language speakers. However, the evaluation of different methodologies requires measurable outcomes. Such outcomes can only be meaningful if the goals of heritage language instruction have been developed and accepted by heritage language professionals and learners alike. Developing such goals based on solid research to determine what can and cannot be achieved within the limits of a reasonable amount of instruction is the greatest challenge we are facing at the moment.

\section{Conclusions}

Some of the excitement of heritage language study lies in its novelty—new things are always exciting. It is also exciting because it brings together several related fields of inquiry that, unfortunately, are not in the habit of talking to each other: theoretical linguistics, with its emphasis on universal principles of language structure; experimental linguistics, especially the study of comprehension, which stands to gain a lot from working with barely responsive, but readily available, populations; acquisition, which can now compare happy and arrested development, and language teaching and pedagogy, which needs to revisit some of the old tried-and-not-so-true L2 methodologies. 
We have shown that heritage languages are still an unchartered territory, both linguistically and pedagogically, but we would like to end this paper on an optimistic note, underscoring how much these languages have to offer linguistic theory. A parallel that immediately comes to mind is with the study of creoles. Some forty years ago, creoles were the domain of specific language study or sociolinguistics, and no respectable linguist worth his stripes would go near them. As soon as linguists recognized that creole phenomena speak directly to Plato's problem in language, creoles gained visibility in linguistic theorizing. Heritage languages add yet another piece to the puzzle of how a grammar can be acquired under minimal input. Although we are only beginning to understand how heritage languages are structured, the emerging patterns point to interesting differences between complete and incomplete first language acquisition, as well as second language acquisition by heritage speakers and foreign language learners (Montrul 2004b, Ionin 2007). The emerging evidence shows that grown-up heritage speakers do not simply hold on to fossilized, frozen grammars from their childhood (Polinsky in press-a). Instead, the grammar undergoes a reanalysis, but what drives this reanalysis? Answering this question may help us come closer to solving the puzzle of language learning.

Heritage languages also hold another attraction. Since the 1990s, linguists have become increasingly aware that the study of language should no longer be solely the prerogative of introspective investigation. Instead, language is something that can be measured using standard experimental methods, and modeled on the basis of rigorously established data. Nowhere is this paradigm shift more welcome than in studies of those who can barely produce language: children, aphasics, and aging populations. Several 
times in this survey article we have mentioned the fact that heritage speakers often have problems with spontaneous production, which calls for the development of new methods to discover their language knowledge. Unlike children or patients with speech disorders, heritage speakers are easy to find, they are motivated and cooperative, and they may even become active participants, not just experimental subjects, in the study of the extent of their linguistic knowledge.

Finally, not only do heritage language speakers present us with a wonderful linguistic challenge, they are also an untapped national resource. We have surveyed studies showing that heritage speakers have an advantage over L2 learners in re-learning their home language. This advantage may not always be visible and is more apparent in phonology and lexicon than in morphosyntax or discourse structure, but it is a reality nonetheless. The globalization of our economy and recent political turmoils have brought new urgency to the need for corporate and government employees fluent in the languages and customs of the countries with which our nation has political and economic ties. The knowledge possessed by heritage learners places them years ahead of anyone studying the language from scratch. This it only makes sense to give them the opportunity to develop further the abilities they already have. The introduction of heritage language courses reflects the acknowledgment that heritage language speakers are a very special group, and in some sense a severely underutilized national resource; with proper instruction, they are much more likely than any second language learner to achieve nearnative linguistic and socio-cultural fluency. That said, we need to be able to formulate what the 'proper' instruction is to be. This is an exciting and daunting task for language educators. 


\section{REFERENCES}

ACTFL (American Council on the Teaching of Foreign Languages): 1999, Proficiency guidelines - speaking. Foreign Language Annals 33(1). 13-18.

Anderson, Raquel T. 2001. Lexical Morphology and Verb Use in Child First Language Loss: A Preliminary Case Study Investigation. International Journal of Bilingualism 5. 377-401.

$\mathrm{Au}$, Terry, and Janet Oh. 2005. Korean as a heritage language. Handbook of East Asian Psycholinguistics, Part III: Korean Psycholinguistics, Ping Li general editor. Cambridge: Cambridge University Press.

$\mathrm{Au}$, Terry and Laura Romo. 1997. Does childhood language experience help adult learners? The Cognitive Processing of Chinese and related Asian Languages, ed. by Chen, 417-441. Beijing: Chinese University Press.

Au, Terry. K., Leah M.Knightly, Sun-Ah Jun, and Janet S. Oh. 2002. Overhearing a language during childhood. Psychological Science 13. 238-24.

Backus, Ad. 1996. Two in one: bilingual speech of Turkish immigrants in the Netherlands. Tilburg: University of Tilburg.

Backus, Ad. 1999. Mixed Native Languages: A Challenge to the Monolithic View of Language. Topics in Language Disorders 19(4). 11-22.

Bailey, Charles-James N. 1973. Variation and linguistic theory. Arlington, VA: Center for Applied Linguistics.

Bailey, Charles-James N. 1974. Some suggestions for greater consensus in creole terminology. Pidgins and Creoles: Current Trends and Prospects, ed. by David DeCamp and Ian Hancock, 88-91. Washington, DC: Georgetown University Press.

Baker, Colin, and Sylvia Prys Jones. 1998. Encyclopedia of Bilingualism and Bilingual Education. Philadelphia: Clevedon Multilingual Matters.

Bates, Elizabeth, Virginia Marchman, Donna Thal, Larry Fenson, Philip Dale, J. Steven Reznick, Judy Reilly, and Jeff Hartung. 1994. Developmental and stylistic variation in the composition of early vocabulary. Journal of Child Language 21. 85-124.

Bickerton, Derek. 1973. The nature of a creole continuum. Language 49. 640-69.

Bickerton, Derek. 1975. Dynamics of a creole continuum. Cambridge: Cambridge University Press. 
Berman, Ruth A. and Dan I. Slobin. 1994. Relating Events in Narrative: A Crosslinguistic Developmental Study. Hillsdale, NJ: Lawrence Erlbaum Associates.

Brecht, Richard D., and Catherine W. Ingold. 1998. Tapping a national resource: Heritage learners in the United States, ERIC Digest EDO-FL-98-12, ERIC Clearinghouse on Languages and Linguistics, Washington D.C., www.cal.org/ericcll/digest/brecht01.html

Bullock, Barbara, Almeida Jacqueline Toribio, Kristopher Davis, and Christopher Botero. 2004. Phonetic Convergence in Bilingual Puerto Rican Spanish. Proceedings of the West Coast Conference on Formal Linguistics 23. 113-125.

Caramazza, Alfonso, G.H. Yeni-Komshian, and Edgar Zurif. 1974. Bilingual switching: The phonological level. Canadian Journal of Psychology 28. 310-318.

Carreira, Maria. 2004. Seeking Explanatory Adequacy: A Dual Approach to Understanding the Term "Heritage Language Learner". Heritage Language Journal 2 (1). http://www.heritagelanguages.org

Caruso, Marinella. 2004. Attrition in the Verb System of Italian in Australia. Australian Review of Applied Linguistics, supplement 18. 9-24.

Choi, Hye-Won. 2002. Pragmatically-driven morphological change: Paradigm leveling in irregular verbs of American Heritage Korean. Paper presented at the UCSD Linguistics Colloquium, February 2002.

Cozens, Sarah. 2003. Heritage Learners in the Polish Language Classroom. Australian Slavonic and East European Studies 17 (1-2). 27-45.

Cummins, James. 2005. A proposal for action: Strategies for recognizing heritage language competence as a learning resource within the mainstream classroom. The Modern Language Journal 89(4). 585-592.

Dorian, Nancy. 1981. Language death: the life cycle of a Scottish Gaelic dialect. Philadelphia, PA: University of Pennsylvania Press.

Dutkova, Lida. 1998. Texas Czech: An ethnolinguistic study. University of Arizona: Ph.D. dissertation.

Fenson, Larry, Elizabeth Bates, Philip Dale, Judith Goodman, J.Steven Reznick, and Donna Thal. 2000. Measuring variability in early child language: Don't shoot the messenger. Comment on Feldman et al. Child Development 71. 323-328.

Fishman, Joshua .A. 2001. 300-plus years of heritage language education in the United States. Heritage Languages in America: Preserving a National Resource, ed. by J.K. 
Peyton, D.A. Ranard, and S. McGinnis, 81-98. Washington, D.C., and Delta Systems, McHenry, IL: Center for Applied Linguistics.

Gerdts, Donna. 1987. Surface Case and Acceptable Relations in Korean: Evidence from Quantifier Float. Studies in Language 11. 181-197.

Godson, Linda. 2003. Phonetics of Language Attrition: Vowel production and articulatory setting in the speech of Western Armenian heritage speakers.

UCSD: Ph.D. dissertation.

Godson, Linda. 2004. Vowel production in the speech of Western Armenian heritage speakers. Heritage Language Journal 2. http://www.heritagelanguages.org.

Gvozdev, Aleksandr N. 1961. Voprosy izučenija detskoj reči. [Issues in the study of child language] Moscow: Izd. Akad. ped. nauk.

Halmari, Helena. 1997. Government and codeswitching: Explaining American Finnish. Amsterdam: John Benjamins.

Halmari, Helena. 1998. Case-assignment and adverbials in Finnish-English bilingual sentences. Language contact, variation, and change, ed. by Jussi Niemi, Terence Odlin, and Janne Heikkinen. 98-110. Joensuu, Finland: University of Joensuu.

Halmari, Helena. 2005. "I'm forgetting both": L1 maintenance and codeswitching in Finnish-English language contact. International Journal of Bilingualism 9. 397-433.

Ionin, Tania. in press. DST vs. UG: can DST account for purely linguistic phenomena?

Isurin, Ludimila, and Tanya Ivanova-Sullivan. in press. Lost in between. Heritage Language Journal. http://www.heritagelanguages.org

Kagan, Olga, and Kathleen Dillon. 2001. A new perspective on teaching Russian: Focus on the heritage learner. Slavic and East European Journal 45. 507-518. Reprinted in Heritage Language Journal 1, www.heritagelanguages.org.

Kagan, Olga, and Kathleen Dillon. 2003. Heritage speakers' potential for high-level language proficiency. Advanced Foreign Language Learning: A Challenge to College Programs, ed. by Heidi Byrnes and Hiram H. Maxim, 99-112. Boston, MA: Heinle/Thomson.

Kagan, Olga, and Debra Friedman. 2004. Using the OPI to place heritage speakers of Russian. Foreign Language Annals 36(4). 536-545.

Kagan, Olga. 2005. In support of a proficiency-based definition of heritage language learners: The case of Russian. International Journal of Bilingual Education 8. 213-21. 
Kim, Hi-Sun Helen. 2001. Issues of heritage learners in Korean language classes.. The Korean Language in America: Volume 6. Papers from the Annual Conference and Teacher Training Workshop on the Teaching of Korean Language, Culture, and Literature, ed. by Jungho Ree (6 ${ }^{\text {th }}$, Manoa, Hawaii, August 2-5, 2001). 257-274.

Kim, Ji-Hye, Silvina Montrul, and James Yoon. 2006. On the Logophoric Long-Distance Binding Interpretation of the Korean Local Anaphor 'Caki-casin' by Early Bilinguals. Proceedings of the Annual Boston University Conference on Language Development 30, 1: 305-315.

Kwon, Nayoung, and Maria Polinsky. 2005. Heritage language retention: A quantitative study. Heritage Learners: Overcoming Curricular Challenges. Paper presented at the Symposium of the 25th meeting of the South Asian Language Analysis (SALA) roundtable, September 16-18, 2005. http://ling.ucsd.edu/ nayoung/Papers/SALA slides_Heritage $\% 20$ Language $\% 20$ Retentio $\underline{\text { n.pdf }}$

Lee, Dong Jae. 2001. Recent trends in foreign language teaching in the United States: The role of heritage learners. The Korean Language in America: Volume 6. Papers from the Annual Conference and Teacher Training Workshop on the Teaching of Korean Language, Culture, and Literature, ed. by Jungho Ree (6 ${ }^{\text {th }}$, Manoa, Hawaii, August 2-5, 2001). 203-211.

Leisio, Larisa. 2001. Morphosyntactic convergence and integration in Finland Russian. Ph. D. Diss., University of Tampere.

Levine, Glenn. 2000. Incomplete First-Language Acquisition in Bilingual Situations: Yiddish in the United States. Linguistische Arbeiten 426. Max Niemeyer Verlag.

Miyagawa, Shigeru. 2006. Locality in syntax and floated numeral quantifiers in Japanese and Korean. Proceedings of the 14 th Japanese/Korean Linguistic, ed. by Timothy J. Vance and Kimberly Jones, 270-282. Stanford, CA: CSLI.

Montrul, Silvina. 2002. Incomplete Acquisition and Attrition of Spanish Tense/Aspect Distinctions in Adult Bilinguals. Bilingualism: Language and Cognition 5. 39-68.

Montrul, Silvina. 2004a. The Acquisition of Spanish. Morphosyntactic Development in Monolingual and Bilingual L1 Acquisition and in Adult L2 Acquisition. Amsterdam: John Benjamins.

Montrul, Silvina. 2004b. Subject and Object Expression in Spanish Heritage Speakers: A Case of Morphosyntactic Convergence. Bilingualism: Language and Cognition 7. 125142.

NVTC: National Virtual Translation Center: 2006. Language learning difficulty for English speakers 
http://www.nvtc.gov/lotw/months/november/learningExpectations.html.

Oh, Janet. S., Sun-Ah, Leah M. Knightly, and Au, Terry. K. 2003. Holding on to Childhood Language Memory. Cognition 86.B53-B64.

Peyton, Joy K., Donald A. Ranard, and Scott McGinnis (eds.) 2001, Heritage Languages in America: Preserving a National Resource. Washington, D.C., and Delta Systems, McHenry, IL: Center for Applied Linguistics.

Polinsky, Maria. 1995. Cross-linguistic parallels in language loss. Southwestern Journal of Linguistics 14. 87-125.

Polinsky, Maria. 1997. American Russian: Language loss meets language acquisition. In Wayles Browne et al., eds. Formal Approaches to Slavic Linguistics, 370-407. Ann Arbor, MI: Michigan Slavic Publications.

Polinsky, Maria. 2000. The Composite Linguistic Profile of Speakers of Russian in the US. The Learning and Teaching of Slavic Languages and Cultures, ed. by Olga Kagan, and Benjamin.Rifkin, 437-465. Bloomington, IN: Slavica.

Polinsky, Maria. 2003. Review of Zemskaja 2001. Heritage Language Journal 1. http://www.heritagelanguages.org/

Polinsky, Maria. 2005. Word class distinctions in an incomplete grammar. Perspectives on language and language development, ed. by Dorit Ravid and Hava Bat-Zeev Shildrkrodt, 419-436. Dordrecht: Kluwer.

Polinsky, Maria. 2006. Incomplete Acquisition: American Russian. Journal of Slavic Linguistics 14: 161-219.

Polinsky, Maria. in press a. Gender under incomplete acquisition. Heritage Language Journal. http://www.heritagelanguages.org

Polinsky, Maria. in press b. Heritage language narratives. Heritage Language Education: A New Field Emerging, ed. by Donna Brinton, Olga Kagan, and Susan Bauckus.

Mahwah, N.J: Lawrence Erlbaum Associates.

Polinsky, M.: in press c, Without aspect. http://www.fas.harvard.edu/ lingdept/documents/Aspect IA 001.pdf

Rickford, John R. 1987. Dimensions of a Creole continuum: History, texts \& linguistic analysis of Guyanese Creole. Stanford, CA: Stanford University Press.

Roca, Ana (ed.). 2000. Research on Spanish in the United States. Sommerville, MA: Cascadilla Press. 
Roosevelt, Theodore. 1918. The Square Deal in Americanism, in Theodore Roosevelt, The Great Adventure. New York, NY: C. Scribner's Sons.

Sanchez, Rosaura. 1983. Chicano discourse. Rowley, MA: Newbury House.

Seliger, Herbert W., and Robert M.Vago. 1991. First Language Attrition. Cambridge: Cambridge University Press.

Silva-Corvalan, Carmen. 1994. Spanish in Los Angeles. Oxford: Clarendon Press.

Sohn, Ho-min. 2001. The Korean Language. Cambridge: Cambridge University Press.

Sorace, Antonella. 2004. Native language attrition and developmental instability at the syntax-discourse interface: Data, interpretations and methods. Bilingualism: Language and Cognition 7. 143-145.

Sundara, Megha, Linda Polka, and Shari Baum. 2006. Production of Coronal Stops by Simultaneous Bilingual Adults. Bilingualism: Language and Cognition 9. 97-114.

Thal, Donna, Elizabeth Bates, Judith Goodman, and J. Jahn-Samilo. 1997. Continuity of language abilities in late- and early-talking toddlers. Developmental Neuropsychology 13. 239-273.

Thal, Donna, Elizabeth Bates, Mary J. Zappia, and Melinda Oroz. 1996. Ties between lexical and grammatical development: Evidence from early-talkers. Journal of Child Language 23. 349-368.

Toribio, Almeida Jacqueline. 2001. Accessing Bilingual Code-Switching Competence. International Journal of Bilingualism 5. 403-436.

Tsimpli, Ianthi, Antonella Sorace, Caroline Heycock, Francesca Filiaci, and Maria Bouba. 2003. Subjects in L1 Attrition: Evidence from Greek and Italian Near-Native Speakers of English. Proceedings of the Annual Boston University Conference on Language Development 27. 787-797.

Tsimpli, Ianthi, Antonella Sorace, Caroline Heycock, and Francesca Filiaci. 2004. First language attrition and syntactic subjects. International Journal of Bilingualism 8. 257278.

Valdés, Guadalupe. 1995. The Teaching of Minority Languages as 'Foreign' Languages: Pedagogical and Theoretical Challenges. The Modern Language Journal 79. 299-328.

Valdés, Guadalupe. 2000. The teaching of heritage languages: An introduction for Slavicteaching professionals, ed. by Olga Kagan and Benjamin Rifkin. The Learning and Teaching of Slavic Languages and Cultures, 375-403. Bloomington, IN.: Slavica. 
Valdés, Guadalupe. 2001. Heritage language students: Profiles and possibilities. Heritage Languages in America: Preserving a National Resource, ed. by Joy K. Peyton, Donald .A. Ranard, and Scott McGinnis, 37-77. Washington, D.C., and Delta Systems, McHenry, IL: Center for Applied Linguistics,

Valdés, Guadalupe, Sonia V. González, Dania López García and Patricio Márquez. in press. Heritage Languages and Ideologies of Language: Unexamined Challenges. Heritage Language Education: A New Field Emerging ed. by Donna Brinton, Olga Kagan, and Susan Bauckus. Mahwah, N.J: Lawrence Erlbaum Associates.

Van Deusen-Scholl, Nelleke. 2003. Toward a definition of heritage language: Sociopolitical and pedagogical considerations. Journal of Language, Identity, and Education 2.3. 211-30.

Wang, Xun (ed.) 1996. A View from Within: A Case Study of Chinese Heritage Community Language Schools in the United States. Washington, DC: The National Foreign Language Center.

Weger-Guntharp, Heather. 2006. Voices from the Margin: Developing a Profile of Chinese Heritage Language Learners in the FL Classroom. Heritage Language Journal 4. http://www.heritagelanguages.org/

Wiley, Terrence G. in press. Chinese "Dialect" Speakers as Heritage Language Learners: A Case Study. Heritage Language Education: A New Field Emerging, ed. by Donna Brinton, Olga Kagan, and Susan Bauckus. Mahwah, N.J.: Lawrence Erlbaum Associates.

Wolfram, Walt, and Natalie Schilling-Estes. 1998. American English: dialects and variation. Malden, MA: Blackwell.

Zapata, Gabriela, Liliana Sanchez, and Almeida Jacqueline Toribio. 2005. Contact and Contracting Spanish. International Journal of Bilingualism 9. 377-395.

Zemskaja, E. A. (ed.) 2001. Jazyk russkogo zarubežja: Ob̌̌čie processy i rečevye portrety [Language of the Russian diaspora: Common processes and speech portraits].Moscow/Vienna: Jazyki slavjanskoj kul'tury/Wiener slawistischer Almanach.

Xiao, Yun. 2006. Heritage learners in the Chinese language classroom: Home background. Heritage Language Journal 4. http://www.heritagelanguages.org/ 